\title{
Testimonio y posición situada en investigación, aportes metodológicos para la reconstrucción de la memoria histórica
}

\author{
Testimony and its position on research, methodological contributions for the reconstruction of \\ historical memory
}

\section{Resumen}

El presente ensayo es un esfuerzo para visibilizar la evolución del pensamiento latinoamericano, recuperando los aportes metodológicos realizados por Ricardo Falla, durante el proceso de investigación que hiciera sobre la masacre perpetrada en la comunidad Chuj de San Francisco de Nentón, Guatemala, en 1982. Su estrategia se fundamenta en la Investigación Acción Participativa, enfocándose en dar validez al testimonio de tres indígenas sobrevivientes. Adquieren especial relevancia los aspectos jurídicos, los testigos deben ser quienes dicen ser, de lo contrario no es posible demandar justicia, el cuerpo del delito tiene que aparecer, en su defecto el delito no existe.

La obra se constituye en un aporte literario, dar voz a las voces ausentes adquiera una connotación de arte. El testimonio es dar vida a la historia que no se contó, San Francisco de Nentón no murió, su tejido social fue disperso y lastimado, es urgente la necesidad de hacer justicia a las comunidades indígenas de Guatemala y América. Ricardo Falla nos dice que es posible hacer investigación situada desde la postura del oprimido.

Palabras claves: Teoría crítica, antropología jurídica, testimonio, narrativa, posición situada, justicia, reconstrucción histórica y pensamiento latinoamericano.

\begin{abstract}
This essay is an effort to make visible the evolution on Latin American's thoughts, recovering methodical contributions made by Ricardo Falla, during the investigation process that he made on the massacre that was perpetrated in the Chuj community of San Francisco de Nentón, Guatemala, in 1982. His strategy is based on the Active Participatory Research (Investigación Acción Participativa), focusing on validating the testimony of three indigenous survivors. The legal aspects acquire special relevance as the witnesses must be who they say they are, otherwise, it is not possible to demand justice. The body of the crime must appear as in its absence the crime doesn't exist. This work constitutes a literary contribution, giving voice to the absent voices through a connotation of art. The testimony is to bring life to the story that was not told, San Francisco de Nentón did not die, his social fabric was dispersed and hurt, the need to do justice to the indigenous communities od Guatemala and America is urgent. Ricardo Falla assures us that its possible to research from the oppressed point of view.
\end{abstract}

Keywords: Critical theory, legal anthropology, testimony, narrative, situated position, justice, historical reconstruction and Latin American thought 
“...Casi todos tenemos (teníamos) esa pena de decir que yo fui víctima de San Francisco. Todos teníamos esa pena... Ya no podíamos levantar la mano (Para decir, "yo lo sufri"). Tenemos pena, tenemos vergüenza" (Mateo Ramos Paiz)

\section{"En última instancia no es el juicio lo que importa" (Sergio Strejilevich)}

\section{Introducción}

En año 2011 fue publicada la obra "Negreaba de Zopilotes"1, a partir de los esfuerzos coordinados por Ricardo Falla ${ }^{2}$, con el propósito de visibilizar los acontecimientos sangrientos ocurridos el 17 de julio de 1982 en la comunidad Chuj de la finca San Francisco de Nentón, Huehuetenango, Guatemala. Fue una masacre que costó la vida a una cifra aproximada de 352 personas, en su momento estos sucesos fueron ocultados por el gobierno guatemalteco y se negó justicia a los sobrevivientes ${ }^{3}$.

El proceso de visibilización de esta masacre fue complejo, sustentado en la reconstrucción de la memoria oral a partir de los testimonios de tres indígenas, todos ellos conocidos como Mateo, presenciaron la masacre y sobrevivieron a ella. Paralelo a los testimonios, se realizan técnicas de indagación en fuentes secundarias y entrevistas con informantes claves.

La metodología es aplicada en el contexto de una investigación acción participativa, buscando cambiar una situación de impunidad por una que se acercara al reconocimiento de los sucesos y la necesidad de restituir el tejido social, así como alcanzar justicia frente al genocidio. La obra adquiere gran connotación, no sólo por su carácter de denuncia social en un país donde la violencia se ha naturalizado, también es un aporte a la investigación acción participativa y al desarrollo del pensamiento crítico.
Recuperar la memoria histórica, cuando ya no se puede revivir a nadie, es una cuestión de ética y justicia social, es necesario considerar la restitución de derechos a las nuevas generaciones o por lo menos obligar a que fenómenos similares no se repitan.

Declaración de las intenciones que guían al indagador y su posición situada

En este aspecto es importante aclarar que Ricardo Falla no tiene la intención de visibilizarse a sí mismo como un gran exponente de la antropología o la investigación, le guió su noción de justicia y la necesidad de contribuir a la emancipación de los pueblos indígenas en Guatemala. Actualmente tiene 84 años y lo único que desea es disfrutar el afecto que le brindan las personas con las cuales convive, se le menciona durante el ensayo porque es nuestra obligación expresar reconocimiento a los precursores de las grandes obras humanas.

El testimonio como género narrativo tiene una larga tradición, desde el antiguo testamento que expresa "no darás falso testimonio" en Éxodo (19:16), hasta el nuevo testamento en Juan (21:24) donde explica la importancia del testimonio veraz. La duración histórica atribuida al testimonio abre múltiples interrogantes en el campo de la antropología jurídica, ligados al problema ancestral de la resolución justa de los litigios, configurado en diferentes culturas y momentos históricos.

La realidad es cognoscible a través del lenguaje, susceptible de ser interpretado solamente a partir de las vivencias y explicaciones de los mismos sujetos. Dicho esto, es necesario aclarar que la comprensión cualitativa es orientadora para situarse en la práctica de dialogar para transformar. Ricardo Falla (2011) expresa: "Si antes de denunciar, queremos comprender, a sabiendas que comprender no es excusar, es imprescindible tener en cuenta, que son posibles mezclas de ternura con crueldad." (p. 48)

1 Nota de la Editora: Para un primer acercamiento al texto Negreaba de Zopilotes, se recomienda la lectura de la reseña de Manolo Vela Castañeda publicada en 2012 en el Anuario de Estudios Centroamericanos (Vela Castañeda, 2012).

2 Antropólogo, sacerdote jesuita de origen guatemalteco.

3 Nota de la Editora: Esta masacre se contextualiza en una más amplia estrategia contrainsurgente impulsada por los gobiernos militares dictatoriales, contra las diferentes expresiones de disidencia y más específicamente contra el grupo guerrillero URNG, Unidad Revolucionaria Nacional Guatemalteca. Estrategia que con diferentes modalidades se extendió por 36 años de dictadura con un saldo de cerca de 250 mil entre muertos y desaparecidos, hasta la firma de la paz en 1996 (Cardenal, 1996; Bonino, 2016). 
Dialogar con los testigos de la obra 'Negreaba de Zopilotes' es un proceso tan largo como su propio trabajo de comprensión acerca de la masacre ocurrida en San Francisco-Guatemala, así lo dice Ricardo Falla (2011):

El plan genocida ya había comenzado, por lo tanto, en 1981. Pero para agilizar la misma estrategia, darle una mejor integración de fuerzas civiles y militares e implicar elementos sicológicos y culturales, a 23 de marzo de 1982 un grupo de militares de graduación media busca al general Ríos Montt como líder y da golpe de Estado. Después de unos pocos días de receso, las unidades militares que estaban en campaña, prosiguen sus operativos, como la masacre de Xalbal en Ixcán (31 de marzo 1982), donde residían cooperativistas chuj provenientes de El Aguacate. Algunos de ellos huirían a su tierra de origen y darían la noticia en sus aldeas de las masacres del Ixcán. También a San Francisco llegó esa noticia. "Escuchamos pues la noticia, cómo pasa en Ixcán, porque allí se empezaron matar gente.” (p.127)

Las reflexiones y prácticas de indagación de Ricardo Falla, mediatizan y reconstruye el saber que está en los sobrevivientes de la masacre. Los resultados de su indagación no tienen el propósito de constituirle en una personalidad del "arte". El valor de su obra está en el testimonio, la visibilización de las voces que fueron silenciadas en San Francisco, y así lo dice Ricardo Falla (2011):

Porque cuando me puse a escuchar los otros testimonios, después de conocer la narración del testigo principal, iba encontrando circunstancias que lo iluminaban o lo completaban. Enfrascado uno en un hecho histórico y viviendo dentro de él "como si presente me hallase". La escena misma va tomando vida, casi independientemente del autor, y va demandando una recreación más amplia. Ojalá que al exponer yo lo sucedido, pueda ser un introductor a la persona joven que me lea, para que también a ella se le haga viva y le demande más y más reconstrucción como si presente se hallase. (Pág. 1)

Y es importante valorar que dar voz a las voces silenciadas no siempre es posible, sino se construyen movimientos sociales y nuevas voces que le den sentido a los sacrificios. Situarse no es la acción de opinar a favor de algo, situarse es tomar conciencia de las incoherencias del poder legítimo, denunciar para alcanzar transformaciones que contribuyan a transformar la realidad.

\section{Aportes metodológicos. "visibilizando las voces silenciadas"}

En la actualidad existen pocos trabajos realizados en Centro América que evidencien las rupturas sufridas en los tejidos sociales o socio-ecosistemas, en algún momento de sus vidas. La investigación titulada "Negreaba de Zopilotes" se basa en indagaciones coordinadas por Ricardo Falla en el contexto de una investigación acción participativa, donde visibiliza los acontecimientos violentos en Guatemala durante la década de los ' 80 . En este sentido es importante mencionar a Deborah Tannen (1998), quien expresa que aquellos hechos que involucran la muerte de inocentes, no tienen otro lado de la cuestión, lo que debe ser juzgado es el hecho mismo y no la opinión de quienes lo perpetraron (p. 11)

Visibilizar las voces inocentes, no es un proceso que pueda hacerse motivado por la curiosidad científica, involucra un compromiso ideológico y debe estar orientado a devolver a las personas su credibilidad, su noción de justicia social e intentar cerrar las heridas abiertas que surgen posterior a traumas vinculados al genocidio.

El texto ofrece una visión holística del testimonio, a través del cual es posible recuperar las voces del pasado para cambiar las miradas históricas desde el futuro o por lo menos la forma en la que pueden ser narrados los acontecimientos a las nuevas generaciones. Reconstruir la historia a través del dialogo de los saberes y la memoria oral, es asumir el compromiso de generar un conocimiento emergente. Se trata de encontrar lo que no está escrito de manera legítima, encontrar los hilos rojos que se entretejen para reconstruir hechos marginados es una tarea de indagación que se va estructurando, de forma aparentemente azarosa.

Sergio Strejilevich, citado por Ana Forcinito (2012, pág. 31), reivindica el testimonio como espacio de narración y simultáneamente como espacio de reflexión sobre la experiencia narrada en primera persona, pero al mismo tiempo reivindica los afectos que habitan el testimonio sin pensarlo como una reducción apolítica e irreflexiva. Para ello defiende el rol del testimonio en 
la reflexión sobre el pasado y el presente, reivindica al testigo en el ejercicio el poder interpretativo y no sólo de su autoridad narrativa.

La tarea del indagador/a, para alcanzar la credibilidad de lo acontecido, fue minuciosa y extenuante: demostrar que la masacre existió en el tiempo y lugar que se menciona, que los informantes son sujetos sobrevivientes y por ello tienen dentro de sí la vivencia de los otros (emanan sus voces en los relatos). Esto dio lugar a que antropólogos forenses participaran en la búsqueda de los cuerpos, determinando el número de muertos y las causas. En criminalística para que un asesinato sea considerado factual debe existir el cuerpo del delito.

Busca conocer "la realidad sobre la masacre en San Francisco", ¿por qué sucedió la masacre?, la estructura de un acontecimiento que debe ser tipificado como un genocidio (el cómo sucedió), cuál fue el contexto socio-político.

Se adecúan los métodos de indagación, esto determina ¿cómo se va a conocer?, métodos exploratorios, de abordamiento y contraste son orientados a visibilizar una realidad, que como antes se mencionara, permite situarnos "cómo si presente nos hallásemos" y hallándonos presentes mediemos el ¿para qué queremos conocer? y a favor de quien vamos a conocer. Una vez que se ha determinado a favor de quien vamos a conocer, el contra qué y contra quien conocer emerge desde las voces ausentes.

Son comprendidos los siguientes aspectos: 1) Ocurrió realmente la masacre; 2) Como ocurrió la masacre en San Francisco; y 3) Qué elementos de la acción hace que se constituya en un crimen de lesa-humanidad; 4) Cuál es el trasfondo que se oculta desde las dimensiones políticas e ideológicas, que dan origen a este tipo de hechos; y 5) Elementos del contexto socio-cultural que facilitan las condiciones para el desenlace trágico de un conflicto.

\section{Interpretación de la estructura de la masacre}

La masacre fue realizada en un contexto particular, válido dentro de la sonoridad de los relatos, es una estrategia de imposición del poder castrense aprovechando la vulnerabilidad en la que se encontraban los pobladores pacíficos de San Francisco de Nentón, cuya principal ocupación era cuidar el ganado de un militar y la agricultura, caídos en desgracia por la presencia de la guerrilla en zonas aledañas.

El indagador declara con franqueza y metódicamente, cuáles fueron sus pasos para dialogar con los acontecimientos:

1. Identifica su objeto de estudio, escucha de forma enfocada el relato de tres testigos, visualiza los hechos y proyecta su trascendencia hacia el futuro. En este proceder es flexible, planifica entrevistar a dos, en la búsqueda opta por tres informantes.

2. Verifica las agencias, los testigos deben ser realmente quienes dicen ser, otros los deben reconocer como tales. Ellos mismos deben reconocerse como sobrevivientes de la masacre, es un trabajo minucioso de diálogo en donde las intersubjetividades son claves. Se identifican como trabajadores, campesinos, con apariencia de gente humilde, despreciada, no son sinvergüenzas, ni ladrones, ni guerrilleros. Son inocentes y honrados. No llegan a reconocerse como una amenaza.

3. Declara sus intenciones, aplica los principios de la franqueza y la comunicabilidad, en una dimensión horizontal de comunicación con el lector, acepta los vacíos que pueden generar nuevas interrogantes ante los hechos acaecidos. Se sitúa, explica que su testimonio será divulgado desde los pies de los oprimidos.

4. Reconstrucción dialógica de los hechos: las voces silenciadas hablan de sus saberes, dan cuenta de los sucesos, de las emociones, de los contextos, las ingenuidades, dan cuenta de las voces de los otros que ya no están para ser escuchados, como dice Deborah Tannen (1998): "A menudo la verdad está en el complejo medio y no en los extremos simplificados. (Pág. 11)". Durante estos procesos de diálogo, el establecimiento de la empatía como intercambio de subjetividades es crucial, para que las voces personales se transmitan como voces colectivas que se trasladan en el tiempo.

5. La reconstrucción de un tiempo mítico a través del análisis asincrónico, tiene su propio esquema, emergen tres categorías que describen la secuencia lógica de la masacre, como puede leerse a continuación: 
- Develación de la masacre: el paso que da el ejército para establecer una cierta confianza, no infundir temor y evitar la huida

- Imposición de la realidad: la masacre se impone, con todas sus notas culturales, el esquema de lo inteligible se desarrolla

- La maravillosa liberación: los testigos escapan, uno a la luz de sueños revelatorios contados por su familia (el tiempo no es lineal en la representación de esta comunidad indígena), otro de los testigos encuentra señales incongruentes con la vida cotidiana y el tercero encuentra la oportunidad de salvarse en su aparente muerte, soltándose de entre sus hermanos que le tienen aprisionado

La intencionalidad secuencial de los acontecimientos, se evidencian en los relatos que describen:

a. Diálogo con el ejército: "debería llamarse interrogatorio del ejército", los guardias preguntan, los campesinos responden. Uno de los testigos expresa que él creía en la benevolencia del ejército, pues había dado muestras de fidelidad que fueron utilizadas contra la comunidad, deja explícito: “iCómo me engañé!". Es una expresión que deja entrever un sentido de culpa. En tanto, otro testigo legitima su escape, dice: "Tuve razón". Sin embargo, al momento de revivir el recuerdo, aflora la culpa, no comentó sus intenciones con su hijo y su hermano, el testigo mide las acciones realizadas por el ejército y prevé que no sobrevivirá si se queda.

b. Robo antes de matar

c. La masacre constituida: violación de las mujeres, asesinato de mujeres y niñas/os, asesinato de ancianas/os (alguno está comiendo sus corazones), asesinato de los hombres que trabajan, amontonamiento de los cadáveres

d. Celebración de la tarea finalizada, al son de las marimbas y al pie de los altares

\section{Conclusión}

Es necesario leer todos los resultados del proceso para asomarse a algunas conclusiones, el sistema de dominación y conquista no ha variado desde que existen registros históricos en Guatemala. Es conocer la impotencia frente a la desigualdad e inequidad, no para "resistirla" porqué equivale a seguir llevando la esfera a cuestas, sino para cambiarla.

En este estudio se intenta conocer: la existencia de la masacre, la estructura de la masacre y los elementos hacen de ella un genocidio sistemático contra la población indígena y el origen de los acontecimientos. Se conoce a favor de la población indígena y se indaga en contra del sistema político que ordena la masacre. ¿Para qué conocer?, se conoce y reconoce para comprender y denunciar, denunciar con el propósito de obtener justicia, sobre esto Ricardo Falla (2011) declara:

Del holocausto guatemalteco todos tenemos alguna parte. Solo si admitimos esto y lo analizamos sin cargarnos, eso sí, de falsas culpabilidades, podemos resarcir el tejido social y llegar a un encuentro reconciliatorio profundo. Entre víctimas completamente inocentes y asesinos totalmente delincuentes no hay reconciliación posible. (Pág. 145)

La masacre de San Francisco no fue la única, existen una serie de asesinatos y atropellos a la población indígena de la zona, que se fueron desarrollando de forma gradual, habituando a la población a un sistema de violencia y miedo, pareciera que lo más natural que pudo suceder es que todo este conflicto tuviera desenlaces tan trágicos.

La investigación sobre la masacre de San Francisco, ofrece diferentes miradas de los acontecimientos, que van desde los detalles más remotos a inicios del siglo $\mathrm{XX}$, al conflicto de la tenencia de la tierra en Guatemala, hasta el auge turístico de las grandes empresas norteamericanas en el 2010, cuyo origen radica en la constante disputa por los recursos económicos.

Ricardo Falla realiza aportes metodológicos específicos para lograr la visibilización de acontecimientos bélicos, donde la justicia ha sido negada a la población vulnerable. La metodología está propuesta en el con- 
texto de una investigación acción, busca cambiar de una situación no deseada y evolucionar a una situación más justa para los sobrevivientes de una masacre y la población indígena. El texto eventualmente tiene un lenguaje poético, sin embargo, no es una obra literaria, es la sistematización de una serie de hechos violentos que demandan justicia para las poblaciones indígenas que han sufrido genocidio en Guatemala, es una denuncia que pasó por ser reconocida en los tribunales internacionales.

Con los aportes que ha realizado Ricardo Falla, al momento de dirigir estas indagaciones, encontramos que es posible construir la historia oficial a partir de la memoria histórica de los pueblos, es un precedente importante. Además, nos insta a reconocer que es posible construir nuevos relatos para cambiar la mirada de las futuras generaciones, sin que esté plagada de una indulgencia parásita o silencios complacientes, sino del reconocimiento hacia la lucha activa por restituir el tejido social y la libertad de elegir que ha sido arrebatada a los pueblos en América.

\section{Bibliografía}

Bonino, J.C. (2016). La globalización a la centroamericana. Managua: Alcaldía de Managua.

Cardenal, R. (1996). Manual de historia de Centroamérica. San Salvador: Uca Editores.

Falla, R. (2011). Negreaba de zopilotes... Masacre y sobrevivencia: finca San Francisco, Nentón, Guatemala (1871 a 2010). Guatemala: AVANCSO, Asociación para el Avance de las Ciencias Sociales en Guatemala.

Tannen, D. (1998). The Argument Culture. Moving From Debate to Dialogue. United States of America: Library of Congress Cataloging.

Forcinito, A. (2012). Los Umbrales del testimonio. Entre las narraciones de los sobrevientes y las señas de la Posdictadura. Madrid: Iberoamericana.

Vela Castañeda, M. E. (2012). Negreaba de zopilotes... Masacre y sobrevivencia: finca San Francisco, Nentón, Guatemala (1871 a 2010). Ricardo Falla. Guatemala: AVANCSO, Asociación para el Avance de las Ciencias Sociales en Guatemala, 2011. 437 páginas. Anuario de Estudios Centroamericanos, vol. 38

\section{Naví Argentina Rodríguez Rivera}

Naví Argentina Rodríguez Rivera (1965). Licenciada en Ciencias Sociales por la UNAN-Managua (1991). Máster en Investigación Cualitativa (UPOLI-2008) y Políticas Públicas (UNI-2012). Doctorante en Educación y Mediación Pedagógica (UNIAV-La Salle 2017) Post-grado en Planificación estratégica en escenarios Educativos. Docente Horario para la Universidad Nacional de Ingeniería (UNI), facilitadora en Investigación Cualitativa para maestrantes de la Universidad Nacional de Panamá y Facilitadora Virtual de ABACO en Red para los temas de Investigación Cualitativa e Investigación Acción Participativa. Consultora independiente en el tema de Educación e innovación pedagógica, Género, empleabilidad en jóvenes, niñez en riesgo de perder el cuidado parental, Economía y Cultura. Coordinadora de proyectos de formación, evaluadora para programas de educación y coordinadora de conferencias internacionales en Guatemala y Costa Rica. En la actualidad es tutora en trabajos de tesis para maestrantes en Desarrollo Comunitario en tema en el tema visibilización de mujeres desplazadas de guerra en Colombia, resiliencia en mujeres víctimas de violencia intra-familiar en Nicaragua y actualmente asesora de tesis con maestrantes de antropología en Panamá que estudian resiliencia y memoria con productores agrarios. Ha publicado en revistas de sindicalismo específicamente en cultura y relaciones de género (Instituto Sindical para América Central y el Caribe), además de un ensayo sobre Investigación Cualitativa y su relación con la mitocrítica (Revista Esfinge-Universidad Complutense de Madriz). Forma parte de la Red Iberoamericana de Investigación sobre imaginarios y representaciones (RIIR). 